\title{
Structural Changes of Mercaptohexanol Self-assembled Monolayers on Gold and their Influence on Impedimetric Aptamer Sensors
}

Xingxing Xu ${ }^{1}$, Asta Makaraviciute ${ }^{1}$, Shalen Kumar ${ }^{2}$, Chenyu Wen ${ }^{1}$, Martin Sjödin ${ }^{3}$, Eldar Abdurakhmanov ${ }^{4}$, U. Helena Danielson ${ }^{4}$, Leif Nyholm 5 , Zhen Zhang ${ }^{1 *}$

\section{AUTHOR ADDRESS}

${ }^{1}$ Division of Solid-State Electronics, Department of Engineering Sciences, The Ångström Laboratory, Uppsala University, P.O. Box 534, SE-751 21 Uppsala, Sweden

$2{ }^{2}$ School of Biological Sciences, Victoria University of Wellington, Wellington 6140, New Zealand, and AuramerBio Limited, Callaghan Innovation Quarter, 69 Seaview Road, Gracefield, Lower Hutt 5010, New Zealand

3 Nanotechnology and Functional Materials, Department of Engineering Sciences, The Ångström Laboratory, Uppsala University, Box 534, SE-751 21 Uppsala, Sweden

${ }^{4}$ Department of Chemistry-BMC, Uppsala University, P.O. Box 576, SE-751 23 Uppsala, Sweden, and Science for Life Laboratory, Uppsala University, Uppsala, Sweden

${ }_{5}^{5}$ Department of Chemistry, The Ångström Laboratory, Uppsala University, P.O. Box 538, SE75121 Uppsala, Sweden

*Corresponding author: Zhen.Zhang@angstrom.uu.se

\begin{abstract}
This supporting information includes part of materials and methods section, the results of polyacrylamide gel electrophoresis (PAGE) and Quartz crystal microbalance (QCM) for aptamer-P1 hybridization. Moreover, supplementary EIS results as mentioned in the results and discussions section in the manuscript are also provided in this file.
\end{abstract}




\section{Materials}

6-Mercapto-1-hexanol (MCH) $\left(\mathrm{HS}\left(\mathrm{CH}_{2}\right)_{6} \mathrm{OH}, 97 \%\right)$, calcium chloride solution $\left(\mathrm{CaCl}_{2}, 1 \mathrm{M}\right)$, Tris(2-carboxyethyl) phosphine hydrochloride (TCEP, 98\%), magnesium chloride solution $\left(\mathrm{MgCl}_{2}, 1 \mathrm{M}\right)$, sodium chloride $(\mathrm{NaCl}, 99.9 \%)$, tris base, potassium ferricyanide $\left(\mathrm{K}_{3}\left[\mathrm{Fe}(\mathrm{CN})_{6}\right]\right.$, $>99 \%)$ and potassium ferrocyanide $\left(\mathrm{K}_{4}\left[\mathrm{Fe}(\mathrm{CN})_{6}\right]\right.$, $\left.>99.5 \%\right)$ were obtained from Sigma (Germany). $10 \mathrm{mM}$ Tris-EDTA solution (TE, $10 \mathrm{mM}$ Tris, $1 \mathrm{mM}$ EDTA) was obtained from Thermofisher Scientific (Sweden). Sulfuric acid (96\%) was purchased from BASF (Sweden). Ethanol (99.5\%) was supplied by VWR (Sweden). SU-8 2002 was obtained from MicroChem (USA). All chemicals were of analytical grade or better and used as received. All aqueous solutions were prepared in UHQ water with resistivity higher than $18 \mathrm{M} \Omega \cdot \mathrm{cm}$.

The oligonucleotides used were purchased from Integrated DNA Technologies (Canada) with the following sequences:

Non-complementary sequence:

\section{TCGAGATTCACTTGTAGACCAATGC}

The oligonucleotides were hydrated in $10 \mathrm{mM}$ Tris-EDTA buffer (10 mM Tris, $1 \mathrm{mM}$ EDTA) ( $\mathrm{pH}$ 8) yielding a concentration of $100 \mu \mathrm{M}$ and the aliquots were maintained at $-20{ }^{\circ} \mathrm{C}$ for long term storage.

\section{Methods}

\section{Electrode fabrication and preparation}

Gold electrode chips were fabricated on optically polished PYREX borosilicate glass (Präzisions Glas \& Optik, Germany). The $100 \mathrm{~nm}$ thick thermally evaporated gold layer on 10 $\mathrm{nm}$ titanium was patterned by standard UV photolithography and lift-off process. SU-8 2002 photoresist was used to define the $0.0078 \mathrm{~cm}^{2}$ (diameter $1 \mathrm{~mm}$ ) working electrode surface area and the $0.078 \mathrm{~cm}^{2}$ (diameter $3 \mathrm{~mm}$ ) counter electrode area. There were two identical electrodes with different sizes, distributed symmetrically on the same chip (see the Figure S1 for schematic view).

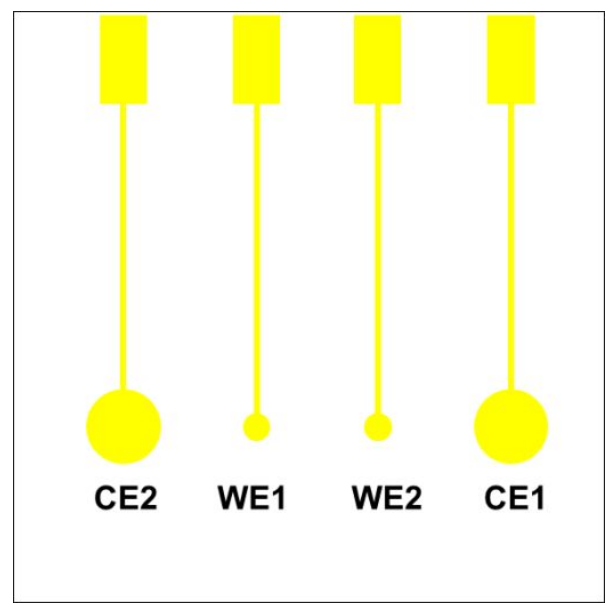


Figure S1. Schematic illustration of the size and location of the gold electrodes on the chips. $\mathrm{W} 1$ and W2 are two working electrodes while $\mathrm{C} 1$ and $\mathrm{C} 2$ are the corresponding counter electrodes. To maintain the same distance between the working and counter electrodes, the electrodes with the same subscripts were used in the same experiment.

Prior to the surface modification, the gold electrodes were pre-treated with $\mathrm{O}_{2}$ plasma $\left(\mathrm{O}_{2} / \mathrm{N}_{2}\right.$, $100 \mathrm{~W}$ ) for five minutes and incubated in ethanol for 30 minutes followed by cyclic voltammetric (CV) scanning in $50 \mathrm{mM}$ sulfuric acid at $100 \mathrm{mV} / \mathrm{s}$ between $-0.4 \mathrm{~V}$ and $1.4 \mathrm{~V}$ until the voltammogram became stable (i.e. approximately five cycles). The cleaning procedure is described in our previous reports. ${ }^{1,2}$ The last cycle was used to determine the effective surface area of the gold electrode.

\section{Surface modification}

The $50 \mu \mathrm{M}$ aptamer was reduced with $50 \mathrm{mM}$ TCEP for one hour at room temperature and diluted with binding buffer yielding a final concentration of $5 \mathrm{nM}$. The aptamer was heated at $95{ }^{\circ} \mathrm{C}$ for five minutes and cooled on ice for ten minutes prior to immobilization. This heating step was used to linearize the aptamer and to decrease the self- and hetero-dimerization of the aptamers hence enabling a more uniform distribution. Then a clean gold electrode was incubated in $5 \mathrm{nM}$ aptamer solution for 17 hours at room temperature. Afterwards, the electrode was incubated in the binding buffer for five minutes with stirring and then rinsed ten times with binding buffer. After washing, the aptamer-functionalized electrode was incubated in $1 \mathrm{mM}$ $\mathrm{MCH}$ in the binding buffer for one hour to remove the nonspecifically adsorbed aptamer and to block the remaining gold surface area. The electrode was washed with binding buffer ten times and directly employed in the electrochemical measurements.

\section{Electrochemical measurements}

The EIS measurements were conducted using a three-electrode cell and a VSP 300 (Bio-Logic, France) electrochemical workstation. All potentials were measured and referred to the $\mathrm{Ag} / \mathrm{AgCl} / \mathrm{sat}$. $\mathrm{KCl}$ reference electrode (ALS Co., Japan). A reference electrode bridge (ALS Co., Japan), i.e., a glass tube with an ion-permeable porous glass tip, was used as a double junction to prevent ions from leaking from the reference electrode into the sample solution during extended measurements. A gold electrode (diameter: $3 \mathrm{~mm}$ ) present on the same chip was used as the counter electrode (see Figure S1). The distance between the working and counter electrodes (center to center) was $8 \mathrm{~mm}$ while the distance between the working and reference electrodes was around $4 \mathrm{~mm}$. All measurements were conducted at room temperature $\left(21{ }^{\circ} \mathrm{C}\right)$ and all solutions were degassed with $\mathrm{N}_{2}$ for 30 minutes prior to the measurements.

\section{Chronocoulometry measurements}

The chronocoulometry measurements were conducted to determine the aptamer surface coverage density as described by Steel et al..$^{3}$ : The chronocoulometry measurements were conducted using $10 \mathrm{mM}$ tris buffer ( $\mathrm{pH}$ 7.4) or $50 \mu \mathrm{M}$ RuHex in $10 \mathrm{mM}$ tris buffer (pH 7.4). Two-step coulometry was performed by stepping from 0 to $-350 \mathrm{mV}$ versus $\mathrm{Ag} / \mathrm{AgCl}$ with a 
pulse period of $250 \mathrm{~ms}$. Prior to each measurement, the electrode was incubated in the electrolyte for around five minutes.

\section{Quartz crystal microbalance (QCM) measurements}

The QCM measurements were conducted with a QCM922A instrument from Princeton Applied Research (USA) using electrodes (diameter: $5 \mathrm{~mm}$ ) made of $300 \mathrm{~nm}$ gold on top of 10 $\mathrm{nm}$ titanium on a $9 \mathrm{MHz}$ quartz crystal. The QCM chips were cleaned and modified in the same way as the chips used in the EIS measurements. The chips were assembled in a dip cell (Princeton Applied Research, USA). During the experiments, the cell was first dipped in a binding buffer solution and a baseline was registered. Next, the cell was transferred to a $95{ }^{\circ} \mathrm{C}$ binding buffer solution containing $15 \mathrm{nM} \mathrm{P} 1$. The temperature of the solution slowly decreased to room temperature while the frequency and resistance response became stabilized and the resistance regained its initial value. The control experiments were conducted using a hot binding buffer solution with or without $15 \mathrm{nM}$ non-complementary sequence.

\section{Polyacrylamide gel electrophoresis (PAGE)}

$1.5 \mathrm{~mm}$ thick 20\% native polyacrylamide gels were prepared using 29:1 acrylamide:methylenebisacrylamide (Acros Organics) in 1xTBE (89 mM Tris, $89 \mathrm{mM}$ boric acid, 2 mM EDTA) (PanReac AppliChem). The gels were run in a vertical electrophoresis cell (XCell SureLock ${ }^{\mathrm{TM}}$, Invitrogen) at $160 \mathrm{~V}$ for one hour at room temperature using a BioRad PowerPac HC $300 \mathrm{~W}$ power supply (Bio-Rad). Each gel was stained for 30 minutes in $50 \mathrm{~mL}$ 1x SYBR Sure DNA gel stain (Invitrogen), which was prepared by diluting $5 \mu \mathrm{L}$ GelRed nucleic acid stain into $50 \mathrm{~mL}$ MilliQ water (1:10000 dilution). No destaining was performed with the polyacrylamide gel.

\section{Evidence for aptamer and P1 hybridization}

\section{PAGE result}

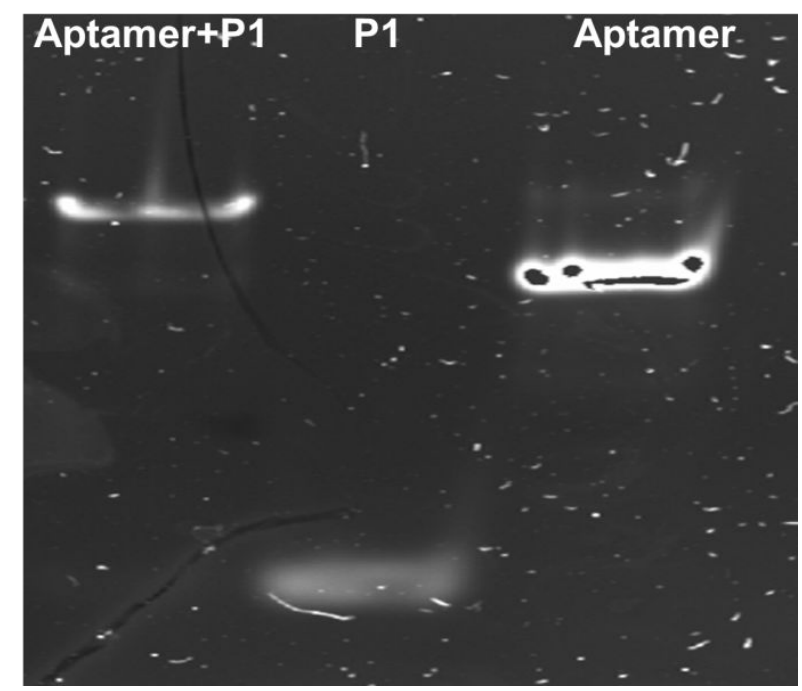

Figure S2. PAGE results after aptamer hybridization with P1. The acrylamide concentration was $20 \%$ 
The hybridization of aptamer with P1 in binding buffer solution was confirmed with PAGE experiments. As shown in Figure S2, three well-separated bands were observed. The electrophoresis speed was $\mathrm{P} 1>$ aptamer $>$ aptamer $+\mathrm{P} 1$, following the increasing mass. This suggests that the aptamer can successfully hybridize with P1 in the binding buffer solution.

\section{QCM results}
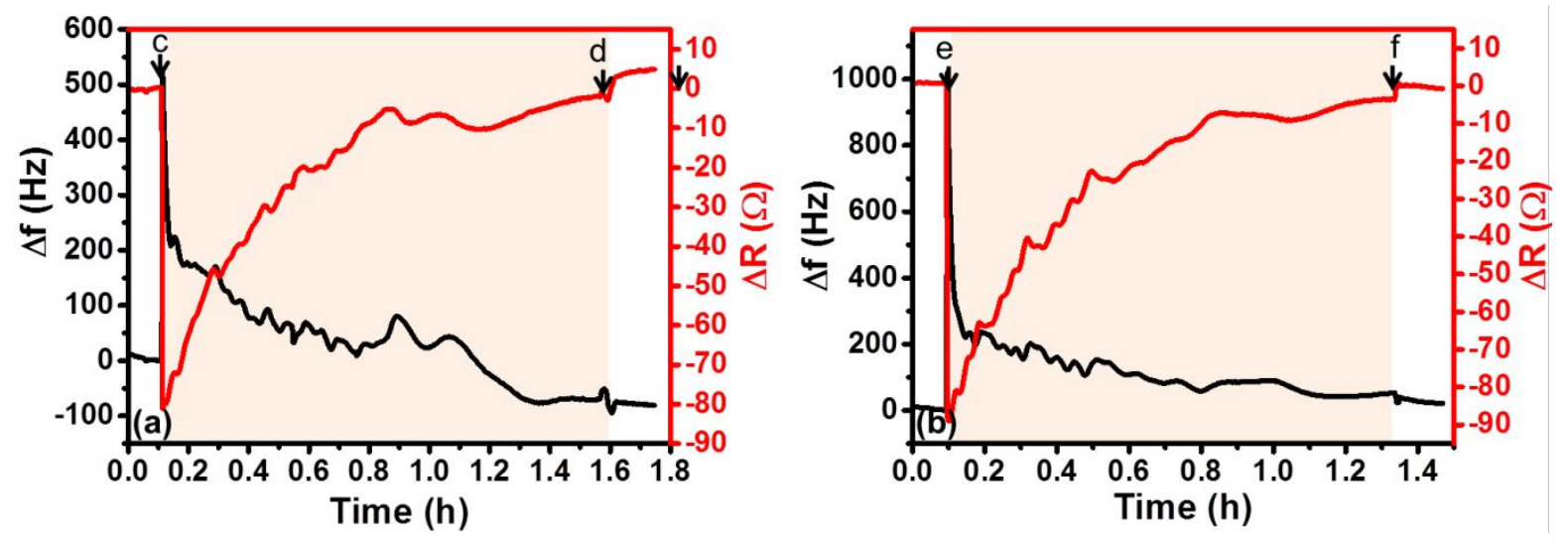

Figure S3. QCM results of aptamer/MCH SAM modified gold interacting with (a) P1 in $95{ }^{\circ} \mathrm{C}$ buffer (b) non-complementary sequence at $95{ }^{\circ} \mathrm{C}$. In Figure (a), at point c, the solution was changed from room-temperature binding buffer to the $95{ }^{\circ} \mathrm{C}$ binding buffer containing $15 \mathrm{nM}$ $\mathrm{P} 1$. At point $\mathrm{d}$, the solution was changed back to the room temperature binding buffer. In Figure (b), at point e, the solution was changed to a $95{ }^{\circ} \mathrm{C}$ buffer containing a non-complementary sequence. At point $\mathrm{f}$, the solution was changed back to the room temperature binding buffer. The black curve is the frequency change while the red cure represents the resistance change.

In the QCM experiments, QCM chips functionalized with aptamer and $\mathrm{MCH}$ mixed SAM were used and the frequency and resistance changes after changing the solution from the binding buffer solution to the denatured P1 solution were monitored. Figure $\mathbf{1 b}$ shows the results of aptamer/MCH SAM interacting with P1. Both the frequency and resistance showed large changes after changing from the room temperature binding buffer to the hot P1 solution (point c in Figure 1b). With the solutions cooling down to room temperature, the resistance slowly changed back to its initial value and the frequency became more and more stable. After changing the solution back to the room temperature binding buffer solution (point $\mathrm{d}$ in Figure S3a), there were no large changes, suggesting that the observed changes in frequency and resistance had been induced by the temperature change. Importantly, the frequency decreased after the hybridization with P1, indicating a mass increase on the electrode surface. Four independent experiments were carried out and the frequency decreased in all cases. The change was in the range between $-25 \mathrm{~Hz}$ and $-80 \mathrm{~Hz}$. Control experiments were also performed in which the aptamer/MCH was incubated with a non-complementary sequence. The results shows, after interacting with the non-complementary sequence, the frequency had increased by $22 \mathrm{~Hz}$, indicating that some weakly bonded aptamers were washed away and that no nonspecific sequence was adsorbed.

Since both the aptamer and P1 can couple with water and the mass of the coupled water on DNA duplex may account for up to $90 \%$ of the total mass, the measured mass change also 
depends on the change in the water content. ${ }^{4}$ However, as the frequency changed after the hybridization while the control experiments showed a different trend, the QCM results can be used as an indirect evidence and qualitatively confirm the hybridization of aptamer and P1 on the gold surface.

\section{Supplementary EIS results}

\section{Fitting examples}

Figure S4 and Table S1 show the example of the measured data and fitted curves with Randles cell equivalent circuit model and the detailed information. As is seen, the fitted curves in the semi-circle region overlap with the measured point, suggesting a good fit.

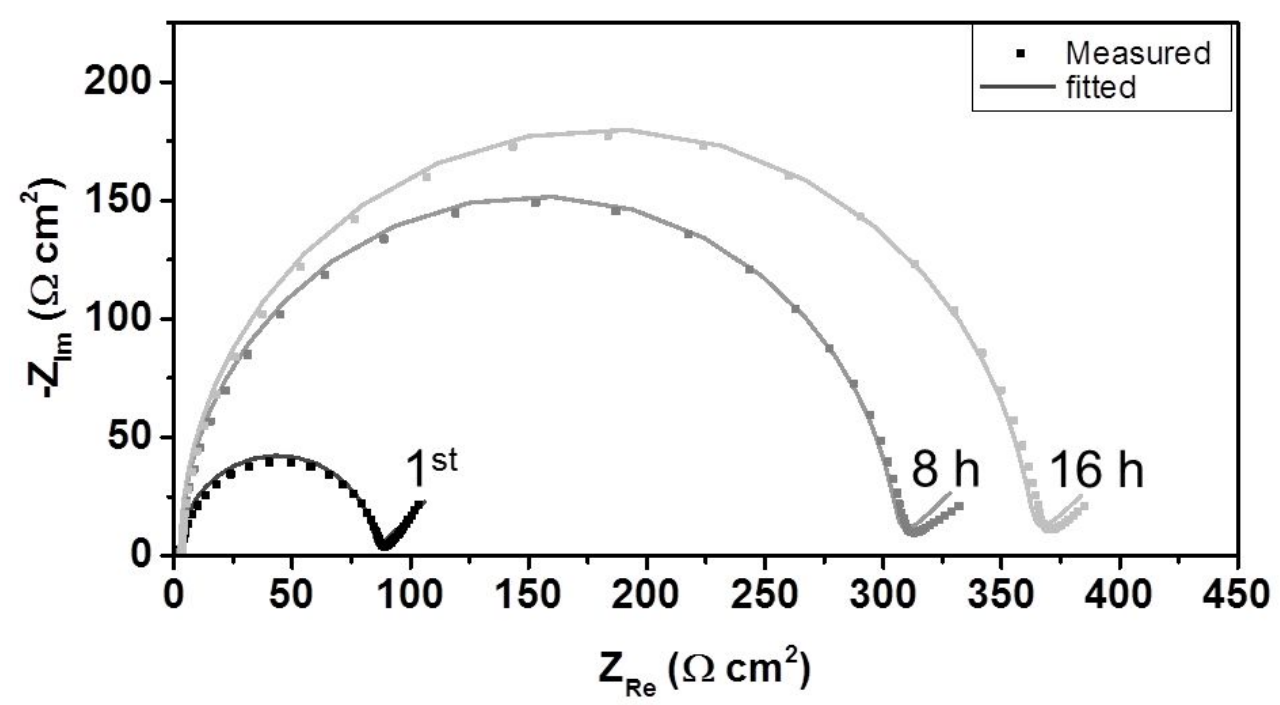

Figure S4. An example of the measured EIS results (dot) and the fitted curves (solid line) with Randles cell equivalent circuit model. The data are taken from 3 curves (i.e., initial cycle, after 8 hours, after 16 hours) in Figure $2 \mathrm{a}$ in the manuscripts.

Table S1. The detailed fitting results for Figure R1 after normalization.

\begin{tabular}{ccccc}
\hline data & Parameters & values & Dev. & $\chi^{2}$ \\
\hline & $\mathrm{R}_{\mathrm{s}}\left(\Omega \mathrm{cm}^{2}\right)$ & 2.99 & 0.002 & \\
& $\mathrm{C}_{\mathrm{DL}}\left(\mu \mathrm{F} / \mathrm{cm}^{2}\right)$ & 3.40 & $6.27 \times 10^{-4}$ & 1.02 \\
& $\mathrm{R}_{\mathrm{CT}}\left(\Omega \mathrm{cm}^{2}\right)$ & 82.13 & 0.003 & \\
& $\mathrm{~A}_{\mathrm{W}}\left(\Omega \mathrm{cm}^{2} \mathrm{~s}^{1 / 2}\right)$ & 17.18 & 0.002 & \\
\hline cycle & & & & 0.65 \\
\hline
\end{tabular}




\begin{tabular}{|c|c|c|c|c|}
\hline & $\mathrm{C}_{\mathrm{DL}}\left(\mu \mathrm{F} / \mathrm{cm}^{2}\right)$ & 4.47 & $2.21 \times 10^{-4}$ & \\
\hline & $\mathrm{R}_{\mathrm{CT}}\left(\Omega \mathrm{cm}^{2}\right)$ & 301.19 & 0.003 & \\
\hline & $\mathrm{A}_{\mathrm{W}}\left(\Omega \mathrm{cm}^{2} \mathrm{~s}^{1 / 2}\right)$ & 19.86 & 0.002 & \\
\hline \multirow{5}{*}{ Cycle after $16 \mathrm{~h}$} & $\mathrm{R}_{\mathrm{s}}\left(\Omega \mathrm{cm}^{2}\right)$ & 3.20 & 0.002 & \multirow{5}{*}{0.48} \\
\hline & $\mathrm{C}_{\mathrm{DL}}\left(\mu \mathrm{F} / \mathrm{cm}^{2}\right)$ & 4.72 & $1.96 \times 10^{-4}$ & \\
\hline & & & & \\
\hline & $\mathrm{R}_{\mathrm{CT}}\left(\Omega \mathrm{cm}^{2}\right)$ & 358.00 & 0.003 & \\
\hline & $\mathrm{A}_{\mathrm{W}}\left(\Omega \mathrm{cm}^{2} \mathrm{~s}^{1 / 2}\right)$ & 18.97 & 0.003 & \\
\hline
\end{tabular}

$* \overline{\mathrm{R}_{\mathrm{S}}}$ is solution resistance, $\mathrm{R}_{\mathrm{CT}}$ is the charge transfer resistance, $\mathrm{C}_{\mathrm{DL}}$ is the double layer capacitance, $\mathrm{A}_{\mathrm{W}}$ is the Warburg coefficient

*Dev. is assimilated to a standard deviation. The mathematics behind the dev. parameters are the following:

$\sigma(\mathrm{aj})^{2}=1 /\left(\mathrm{d}^{2} \mathrm{X}^{2} / \mathrm{d}^{2} \mathrm{a}_{\mathrm{j}}\right)$

with $\mathrm{a}_{\mathrm{j}}=\mathrm{jth}$ parameters $\mathrm{j} ; \mathrm{d}^{2}=$ second derivative; $\sigma\left(\mathrm{a}_{\mathrm{j}}\right)^{2}=$ covariance

* $\chi^{2}$ gives an estimation of the distance between the real data and the simulated data

$$
\chi 2=\sum_{i=1}^{n} \frac{\mid Z_{\text {meas }}(\mathrm{i})-\mathrm{Z}_{\text {simul }}\left(\mathrm{f}_{\mathrm{i}}, \text { parameter }\right) \mid}{\left|\mathrm{Z}_{\text {meas }}(\mathrm{i})\right|}
$$
measurements while conditioning 


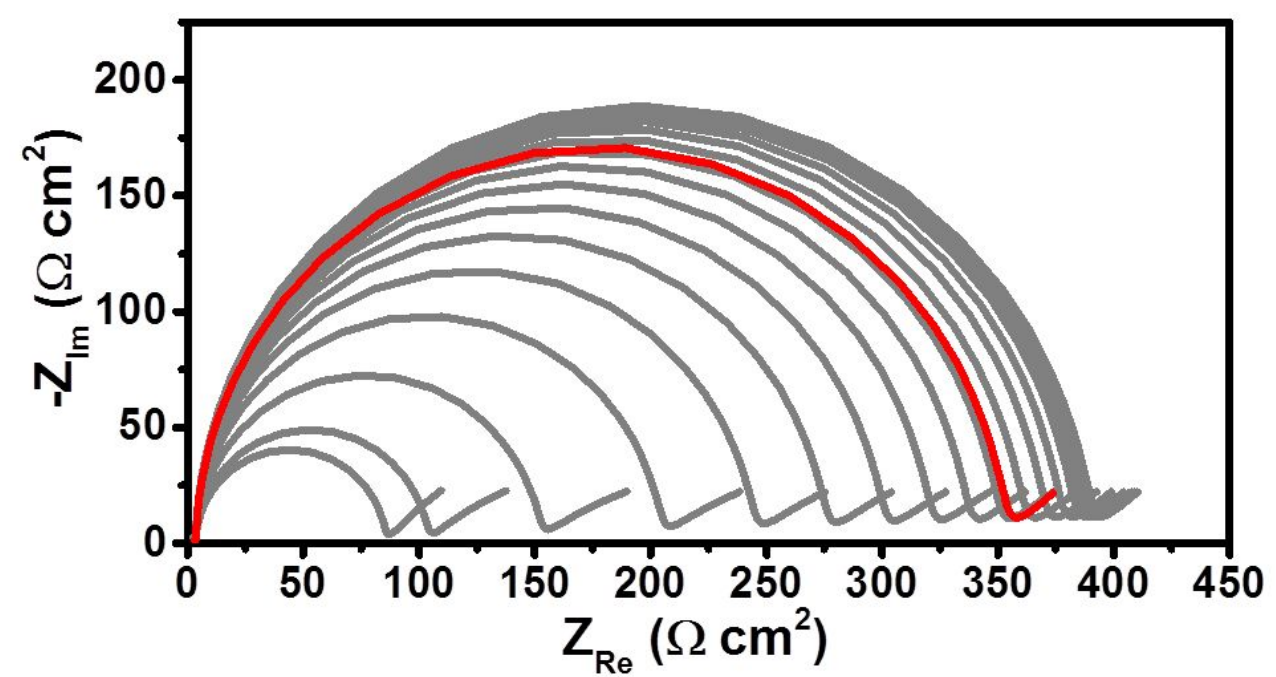

Figure S5. Comparison of the faradaic EIS drift for an aptamer/MCH modified electrode in the buffer solution containing $10 \mathrm{mM}$ ferri- and ferrocyanide during repeated measurements (grey) as well as after conditioning in the measurement solution for the same time as the last cycle for the repeated measurements(red). The faraday EIS measurements were conducted at room temperature in the buffer solution containing $10 \mathrm{mM}$ ferri and ferrocyanide.

Table S2. The example $\mathrm{R}_{\mathrm{CT}}$ values obtained for the aptamer/MCH and $\mathrm{MCH}$ modified gold electrodes

\begin{tabular}{|c|c|l|}
\hline $\begin{array}{c}\mathrm{R}_{\mathrm{CT}} \text { of aptamer/MCH } \\
\text { modified electrode after } \\
\text { stabilization }\left(\Omega \cdot \mathrm{cm}^{2}\right)\end{array}$ & $\begin{array}{c}\mathrm{R}_{\mathrm{CT}} \text { of } \mathrm{MCH} \text { modified } \\
\text { electrode after stabilization } \\
\left(\Omega \cdot \mathrm{cm}^{2}\right)\end{array}$ & Remarks \\
\hline 343 & 257 & \multirow{2}{*}{ Electrodes on the same chip } \\
\hline 380 & 230 & Electrodes on the same chip \\
\hline 242 & 351 & \multirow{2}{*}{ Electrodes on the same chip } \\
\hline 385 & 345 & 437 \\
\hline 354 & 431 & \\
\hline
\end{tabular}

Faradaic impedance for an aptamer/MCH electrode prior to and after hybridizing with P1 


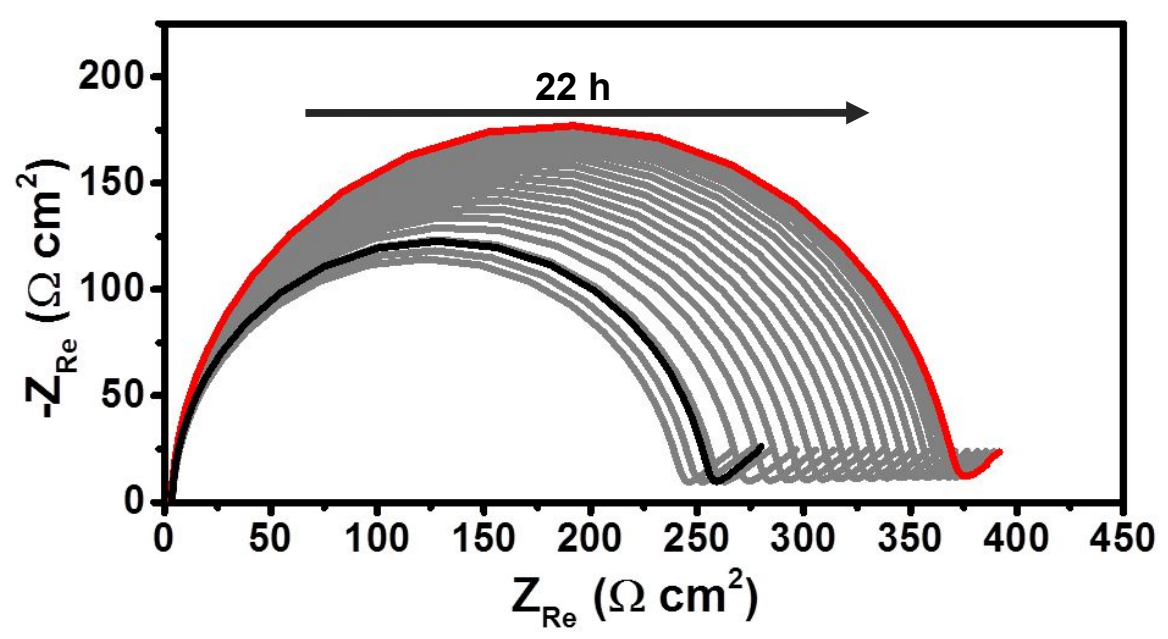

Figure S6. Faradaic impedance for an aptamer/MCH electrode prior to and after hybridizing with P1. The faraday EIS measurements were conducted in the buffer solution containing 10 $\mathrm{mM}$ ferri and ferrocyanide at room temperature. The black curve represents the stabilized curve for the aptamer/ $\mathrm{MCH}$ electrode (i.e. the curve prior to the hybridization) while the grey curves represent for the curves obtained at different times after the hybridization. The time interval between two nearby curves was about one hour. The red curve represents the stabilized result for the hybridized aptamer/MCH electrode.

Comparison of the results for a MCH modified electrode with or without repeated measurements while conditioning

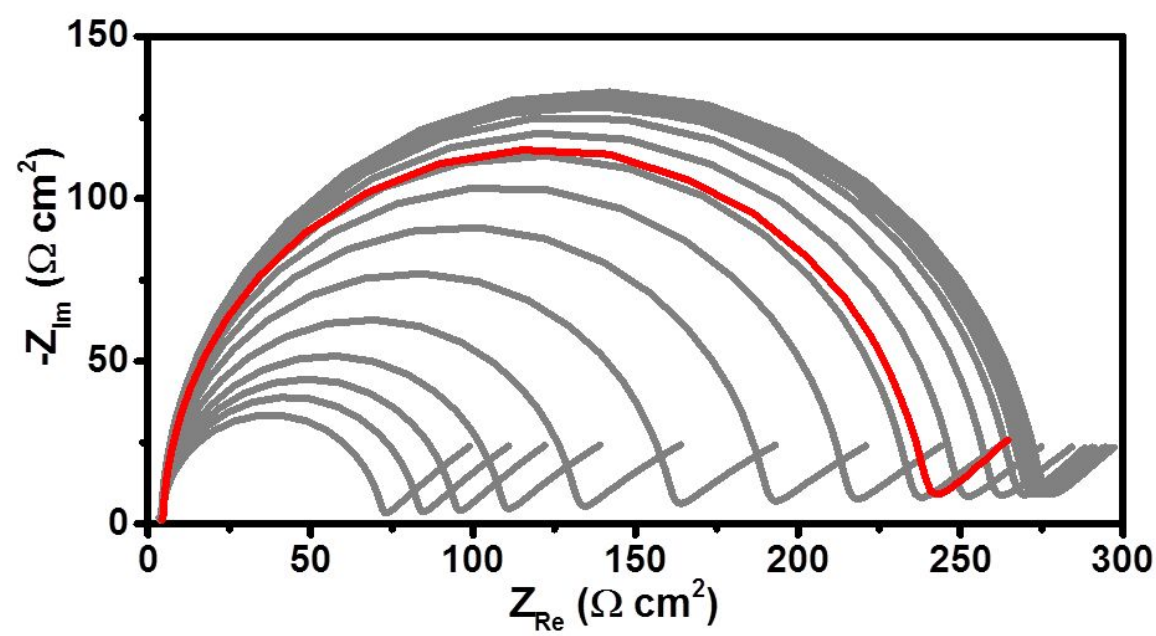

Figure S7. Comparison of the faradaic EIS drift for a $\mathrm{MCH}$ modified electrode in binding buffer solution containing $10 \mathrm{mM}$ ferri- and ferrocyanides during repeated measurements (grey) as well as after conditioning in the measurement solution (red). The faraday EIS measurements were conducted at room temperature in the buffer solution containing $10 \mathrm{mM}$ ferri and ferrocyanide.

Faradaic EIS drift for an aptamer/MCH and MCH modified gold electrode after incubation in the hot hybridization buffer 

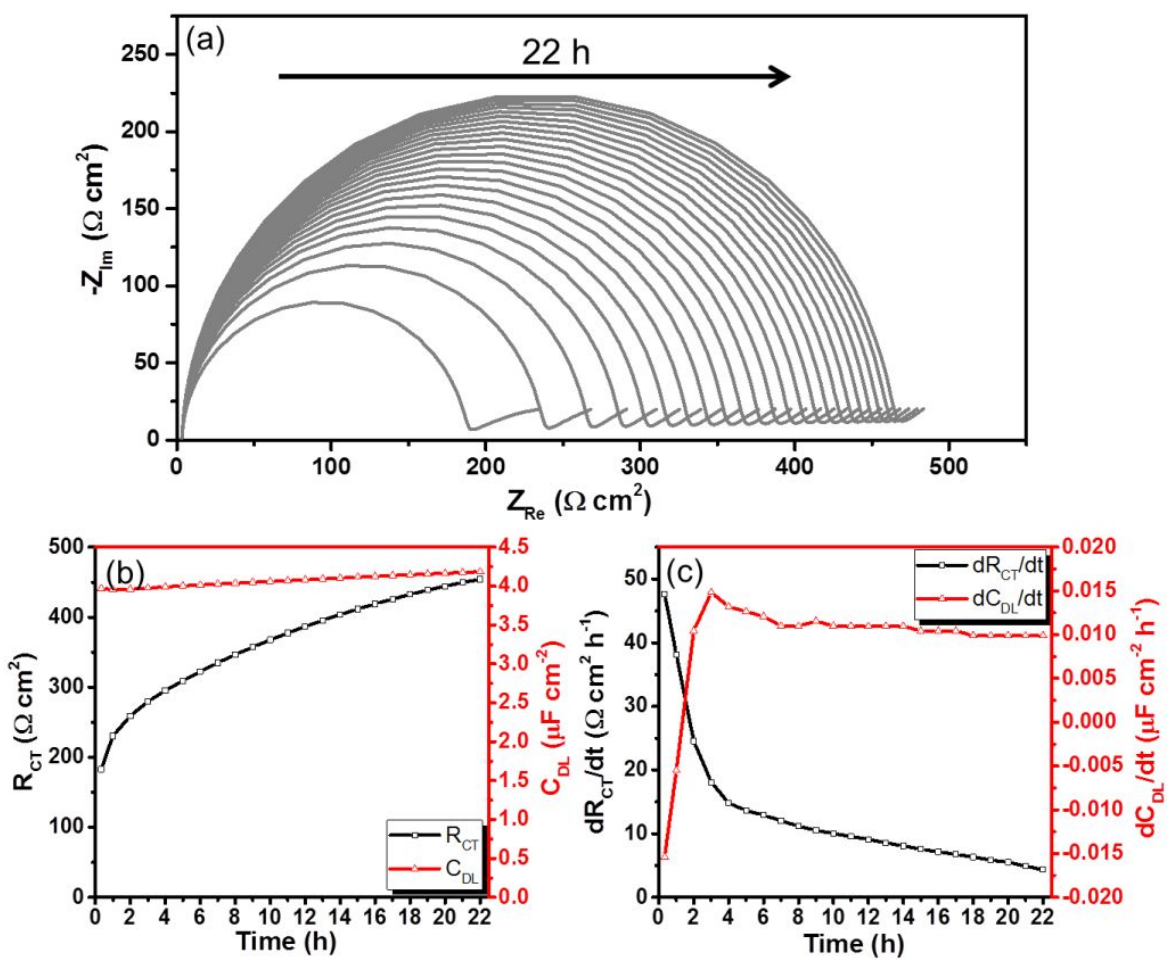

Figure S8. Faradaic EIS signal drift for an aptamer/MCH modified gold electrode after incubation in the hot hybridization buffer. (a) Nyquist plots; (b) The evaluated $\mathrm{R}_{\mathrm{CT}}$ and $\mathrm{C}_{\mathrm{DL}}$ values as a function of time; (c) The $\mathrm{R}_{\mathrm{CT}}$ and $\mathrm{C}_{\mathrm{DL}}$ change rates versus time. The EIS measurements were conducted at room temperature in the buffer solution containing $10 \mathrm{mM}$ ferri- and ferrocyanide.
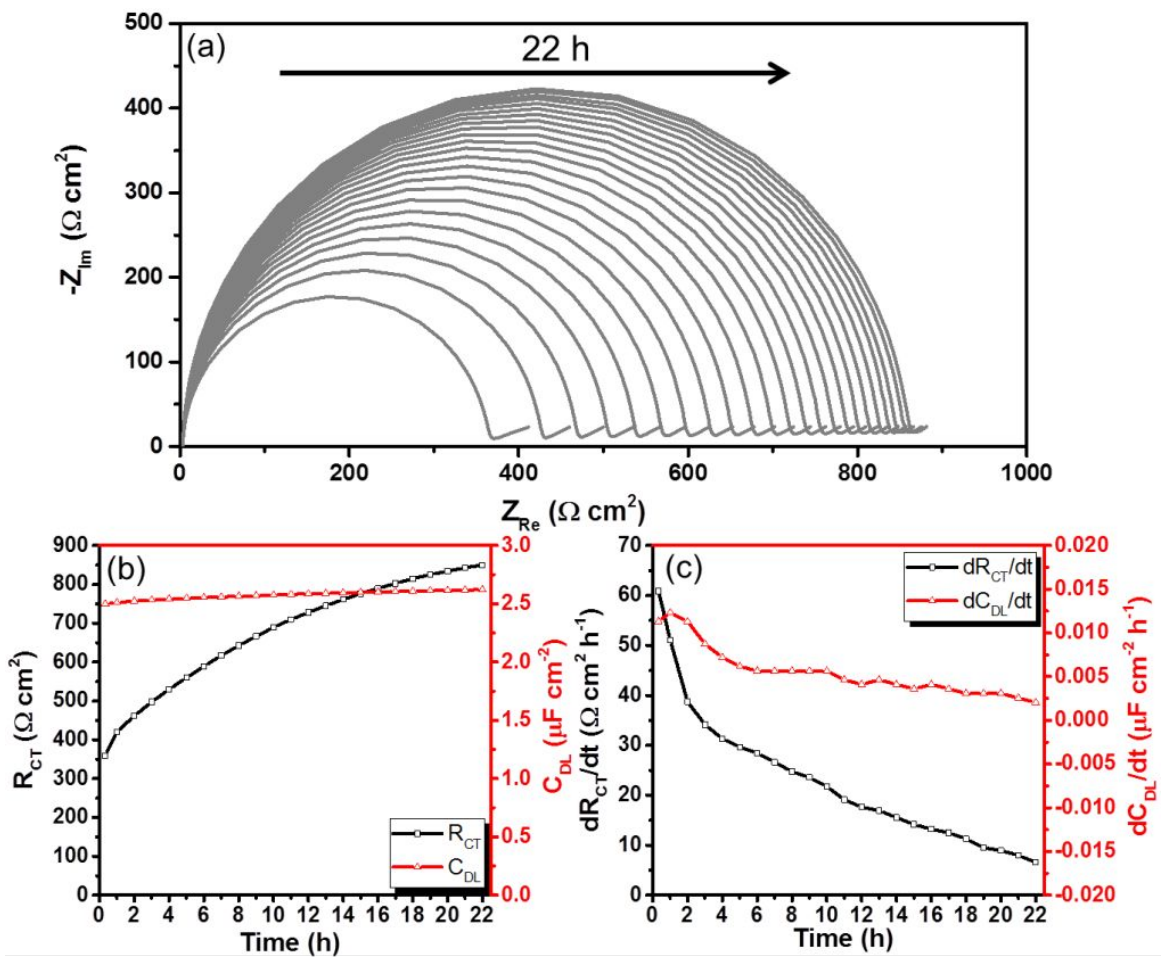
Figure S9. Faradaic EIS signal drift for a MCH modified gold electrode after incubation in the hot hybridization buffer. (a) Nyquist plots; (b) The evaluated $\mathrm{R}_{\mathrm{CT}}$ and $\mathrm{C}_{\mathrm{DL}}$ values as a function of time; (c) The $\mathrm{R}_{\mathrm{CT}}$ and $\mathrm{C}_{\mathrm{DL}}$ change rates versus time. The EIS measurements were conducted at room temperature in the buffer solution containing $10 \mathrm{mM}$ ferri- and ferrocyanide.

\section{Reference}

(1) Makaraviciute, A.; Xu, X.; Nyholm, L.; Zhang, Z. Systematic Approach to the Development of Microfabricated Biosensors: Relationship between Gold Surface Pretreatment and Thiolated Molecule Binding. ACS Appl. Mater. Interfaces 2017, 9 (31), 26610-26621. https://doi.org/10.1021/acsami.7b08581.

(2) Xu, X.; Makaraviciute, A.; Pettersson, J.; Zhang, S.-L.; Nyholm, L.; Zhang, Z. Revisiting the Factors Influencing Gold Electrodes Prepared Using Cyclic Voltammetry. Sens. Actuators B Chem. 2019, 283, 146-153. https://doi.org/10.1016/j.snb.2018.12.008.

(3) Steel, A. B.; Herne, T. M.; Tarlov, M. J. Electrochemical Quantitation of DNA Immobilized on Gold. Anal. Chem. 1998, 70 (22), 4670-4677. https://doi.org/10.1021/ac980037q.

(4) Larsson, C.; Rodahl, M.; Höök, F. Characterization of DNA Immobilization and Subsequent Hybridization on a 2D Arrangement of Streptavidin on a Biotin-Modified Lipid Bilayer Supported on SiO2. Anal. Chem. 2003, 75 (19), 5080-5087. https://doi.org/10.1021/ac034269n. 